\title{
THERMOGRAPHIC INVESTIGATIONS \\ SUPPORTING DIAGNOSIS FOR FONDATIONAL AND CONSERVATIVE ISSUES: the case study of Anime Sante del Purgatorio Church in Caccamo, Sicily-Italy
}

by $\mathrm{A}$. Bianco

\begin{abstract}
*PAU Dept., University of Reggio Calabria, via Melissari 1-89100 Reggio Calabria, Italy, alessia.bianco@unirc.it
\end{abstract}
\section{Anamnesis}

The Anime Sante del Purgatorio Church is a large religious building, with an annexed monastery, built in the Caccamo Municipality-Sicily-Italy in XVIII century and realized on an expansion area of the ancient medieval village; in fact it is placed under the rock of medieval Castel and on a very steep site, characterized by not much suitable geotechnical characteristics of foundation terrains. Moreover the Church is on ancient canals of rain water flow, coming from the medieval village and it is also close to some cisterns used by Castel to save rain water and provided of canals for its flow, in case of excessive rain and in function of their capacity.

\section{Investigation}

This is These issues determined on the Anime Sante del Purgatorio Church a no extensive but, at same time, serious problem of structural cracks and above all a lot of degradation issues, caused by going back humidity, compromising the material conservation of interior lower masonry of building, decorated with valuable stucco and plasters or with marbles and a peculiar copper application. Bisedes this problem causes an alteration of thermohigrometric comfort conditions, compromising its functional use.

However, every information about a presence of cisterns and canals was close to the Church was indicated by historical documents and it was not possible to verify directly their characteristics and if they were out of order or if in case of rain they were efficient.

For this reason war projected and realized a diagnostic investigative campaign, aimed to monitor the Church inside (where were most evident degradation and structural cracks) and outside (where we supposed a presence of canals); this monitoring was conducted realizing at same time an extensive thermographic mapping and a thermohigrometric recording, made comparing the results obtained in sunny and rainy days. The repetition of the same investigative protocol in different climatic conditions permitted to verify the incidence of rain flow and to have a confirmation of presence of supposed canals with the individualization of others (figure 1).

\section{Results}

The capability of this investigative methodology to individualize the area more exposed to this peculiar conservative vulnerability permitted also to define a simple intervention project, which contains realization of an alternative system of underground canals, to intervene on the causes, and little works of cracks repair and foundation isolation with a aerating trench and material consolidation of decorations, to intervene on the degradation. Finally capability to repeat the same investigative protocol after realization of intervention gives an opportunity to value, in qualitative and quantitative terms, its efficacy, on a short time, and its efficiency on a long time (figure 2).

\section{REFERENCES}

[1] Harvey D., Schuller P. M.. "Nondestructive Evaluation: Structural Performance of Masonry." APT Bulletin vol. 41.2/3, pp-11-18, 2010.

[2] Prakash P., "Investigations on Ancient Masonry Structures Using Infrared Thermography." University College of Engineering:Hyderabad, India, 2007

[3] Rosina E., Spodek J.. "Using Infrared Thermography to Detect Moisture in Historic Masonry: A Case Study in Indiana." APT Bulletin 34.1, pp.11-16, 2003. 


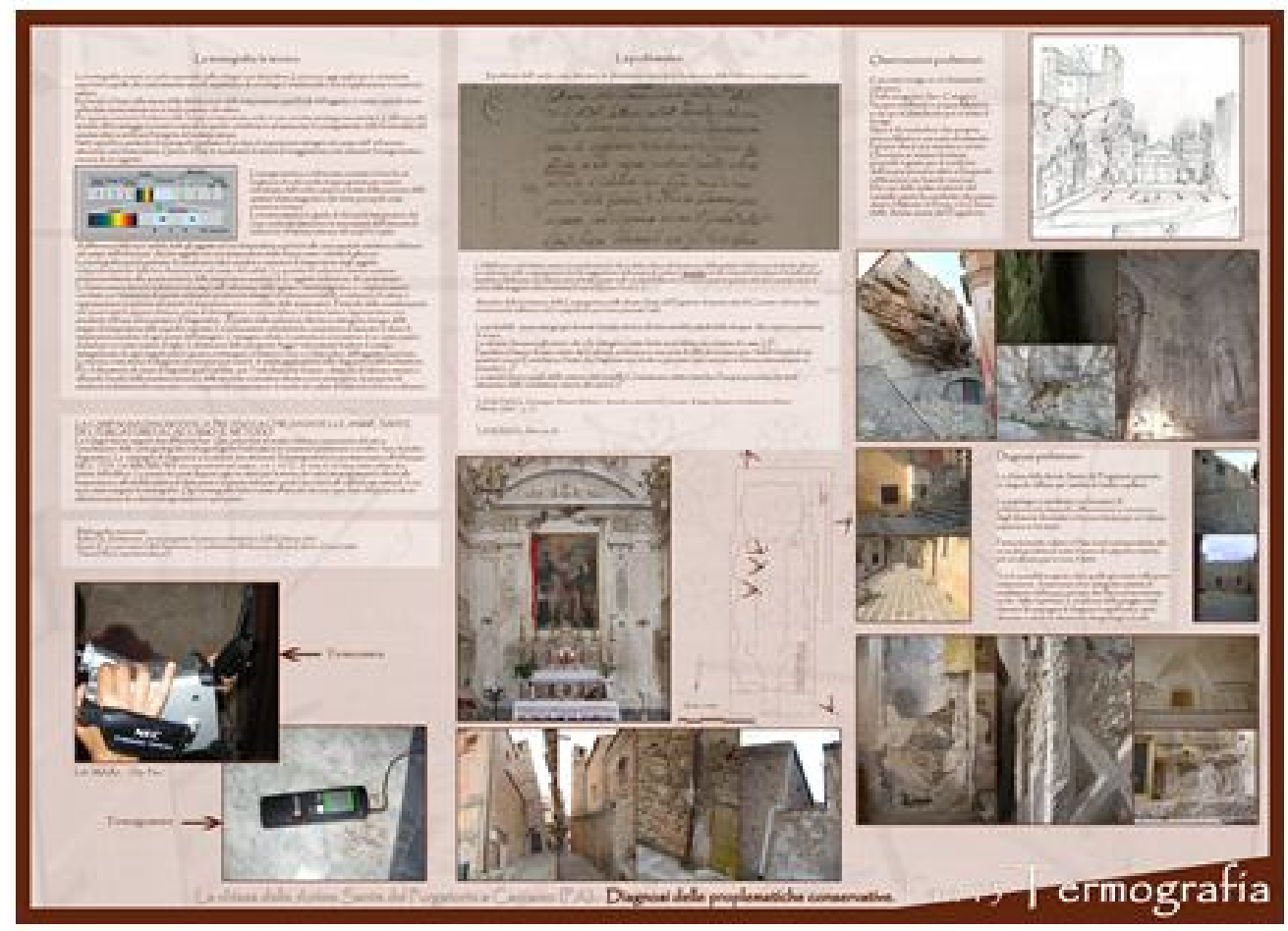

Fig. 1. The Anime Sante del Purgatorio Church, TI investigation

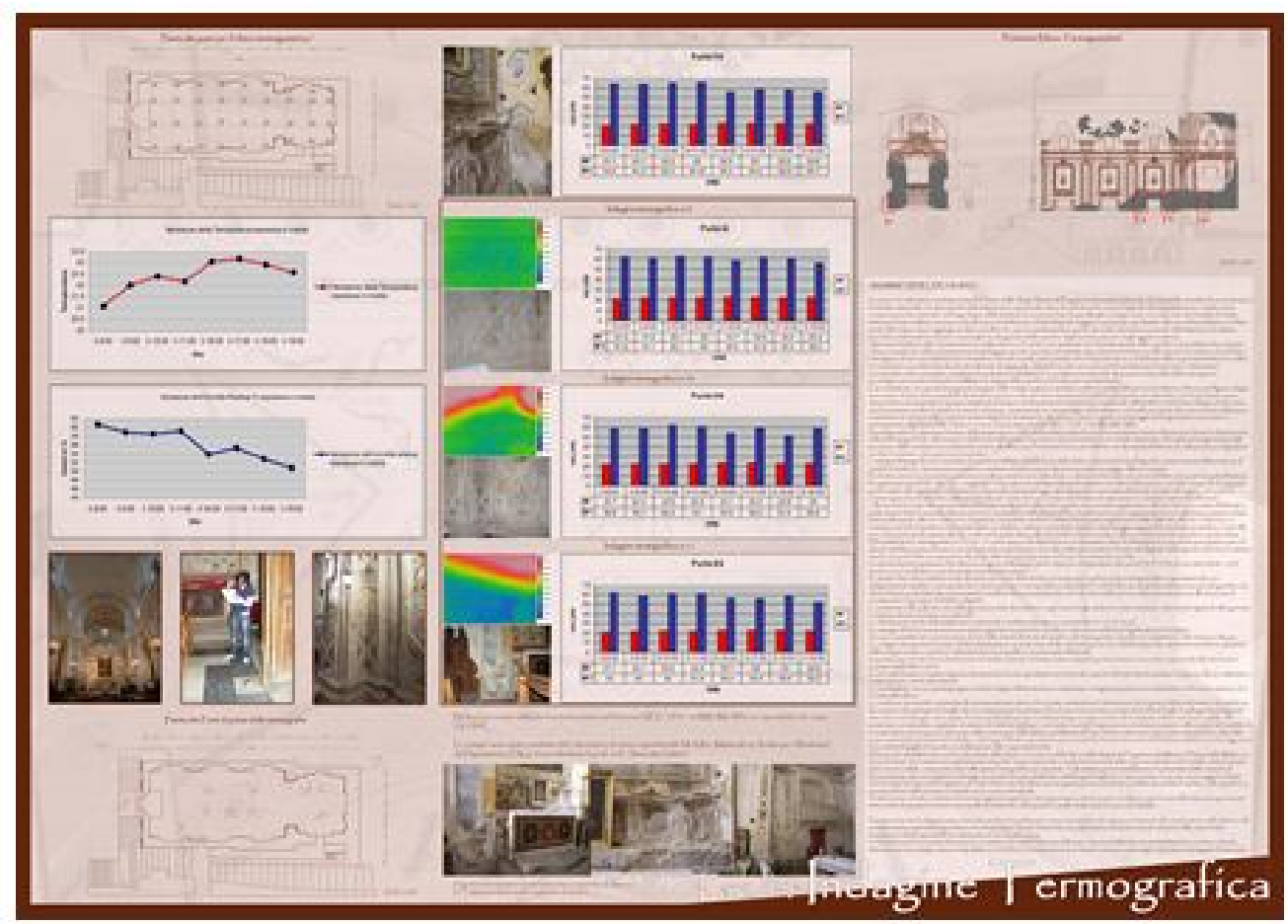

Fig. 2. The Anime Sante del Purgatorio Church, TI results 